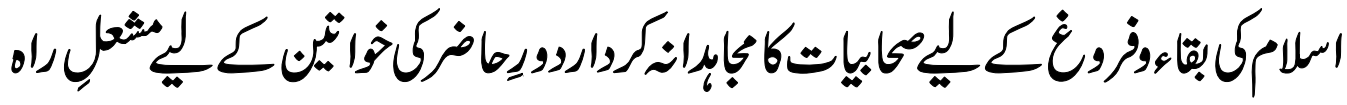

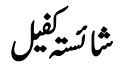

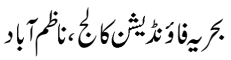

\section{تلذيص المقاله}

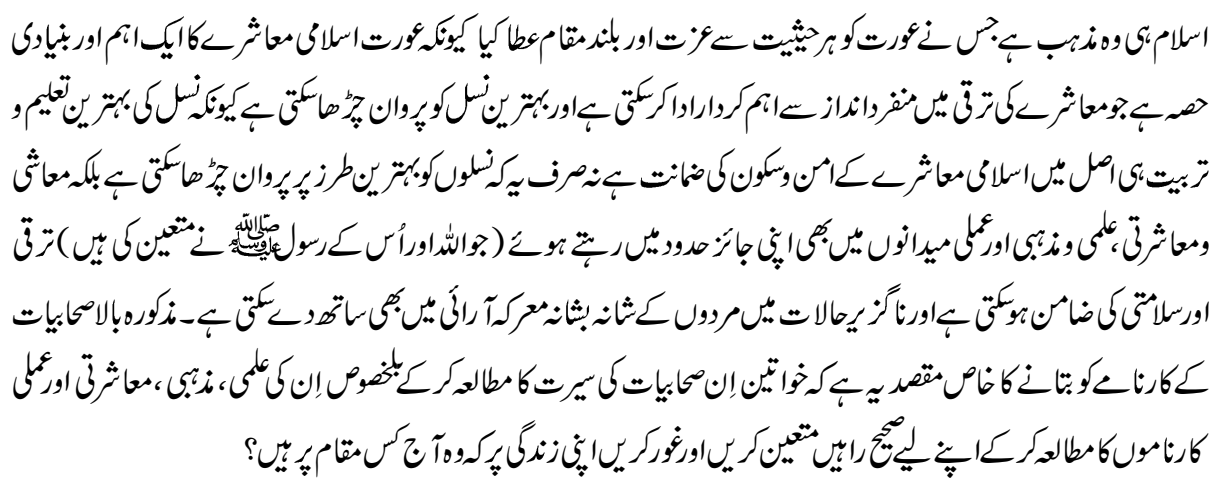

Abstract

Islam is the religion which has given a woman higher position and respect in every way, because a woman is a very important and basic part of the society, who plays a unique and vital role in the society and can nurture the generation in far better ways. A generation's proper education and nurturing is Islamic society's source for peace and prosperity. Not only does she up-brings the generation in the best possible way but she also helps in the development of momentary, social, educational and religious field. She plays her role by staying in her limits (which Allah and His Prophets have suggested). In unavoidable circumstances she can also go abreast with men in every way. The main reason for mentioning the achievements of the following 'Sahabeeyat' is that women should go through the life history of these 'Sahabeeyat' especially their education, religious,social and practical achievements and select the right path and think that where do they stand in their lives.

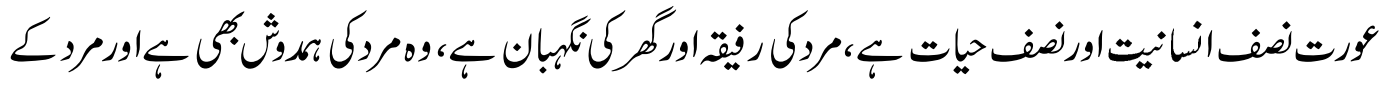

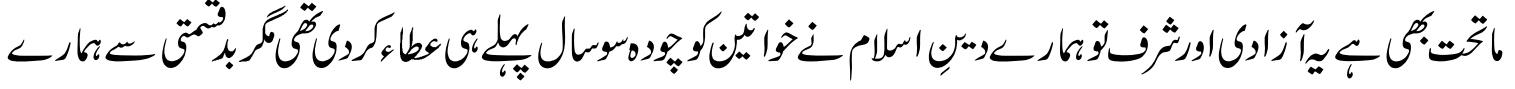

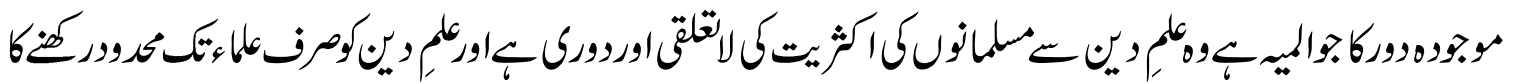

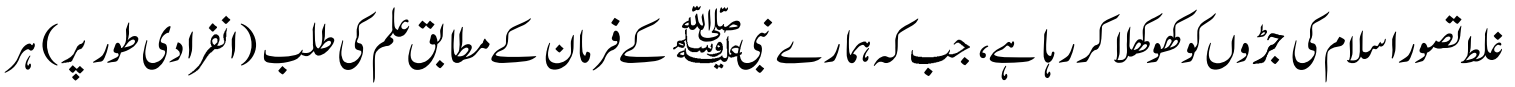

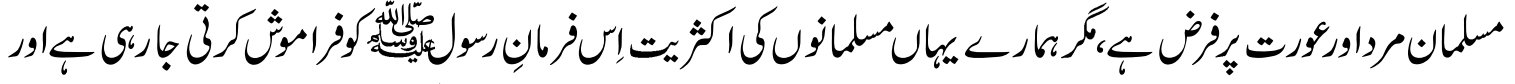

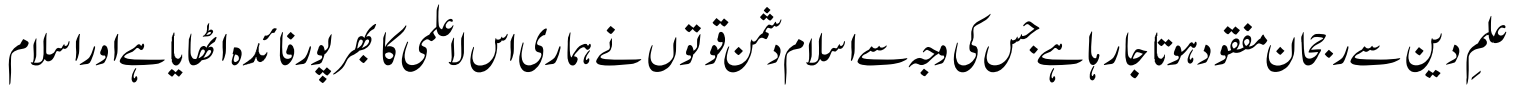




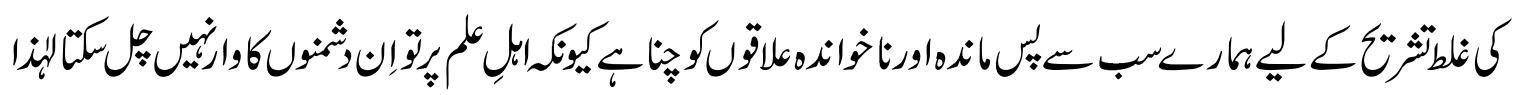

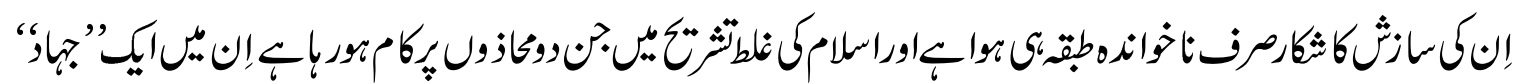

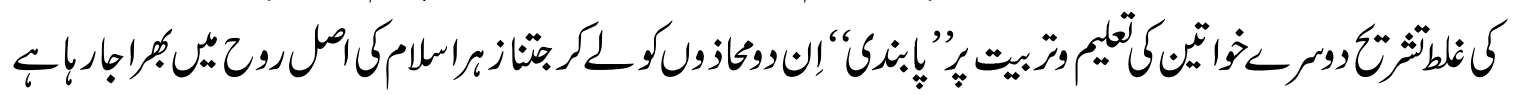

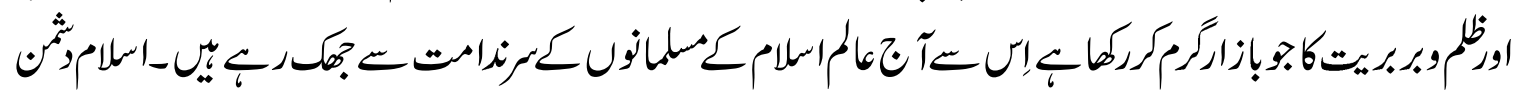

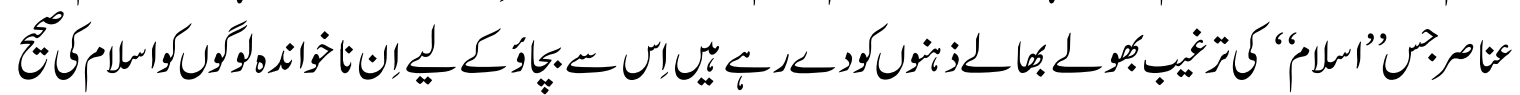

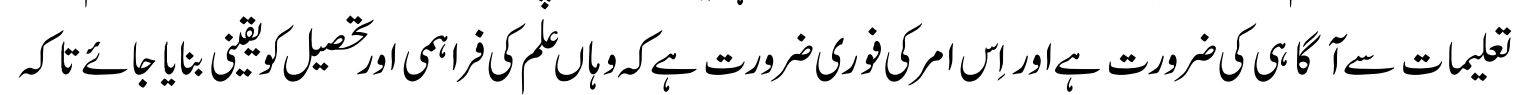

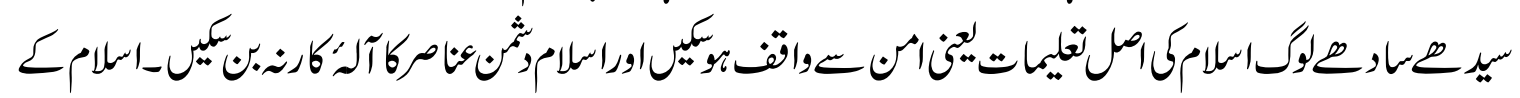

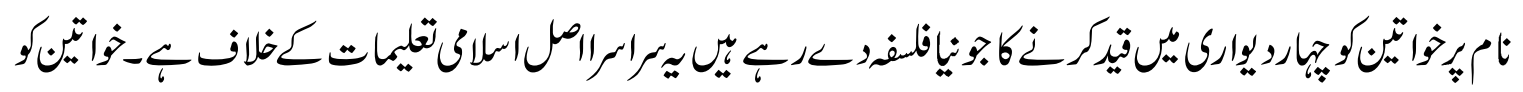

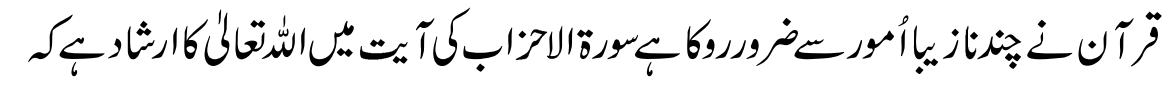

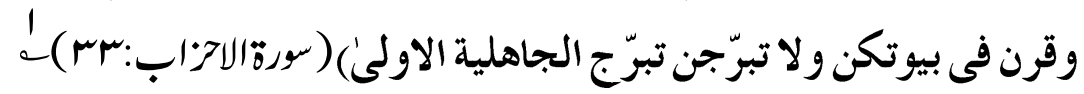

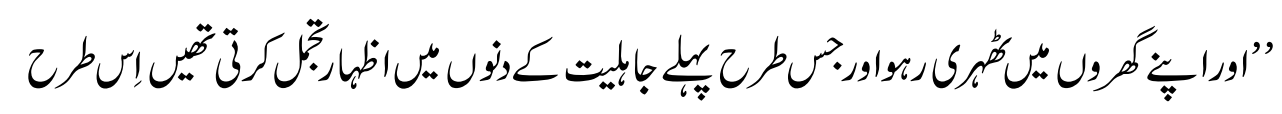
تزبم::

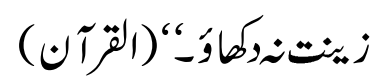

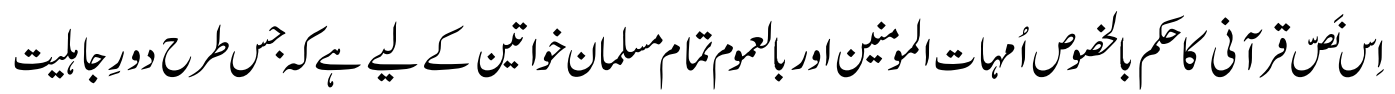

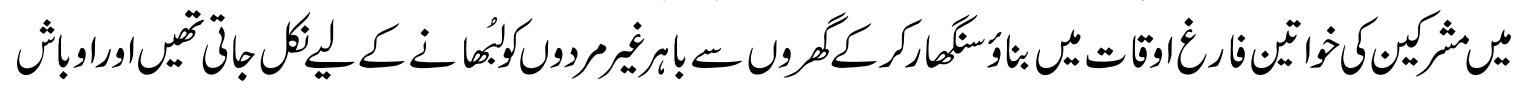

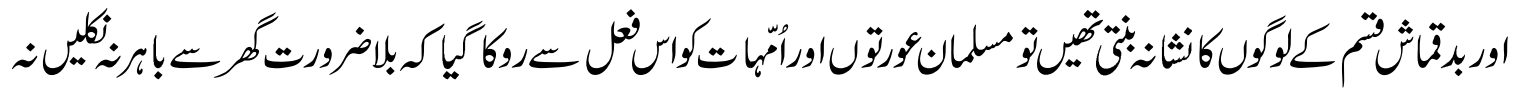

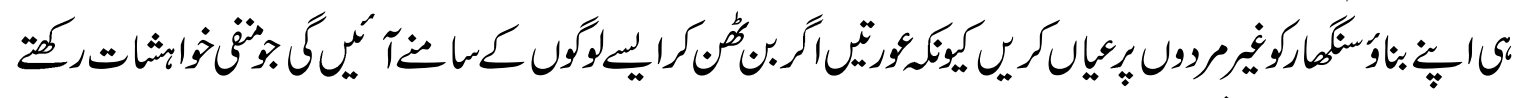

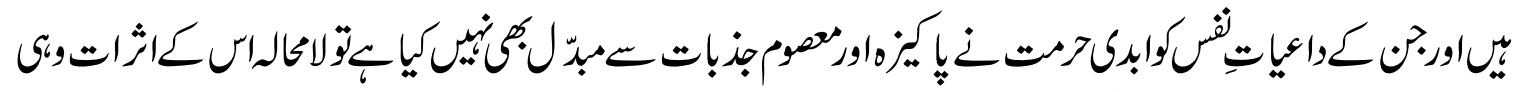

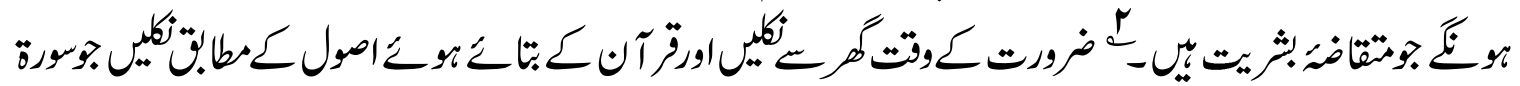

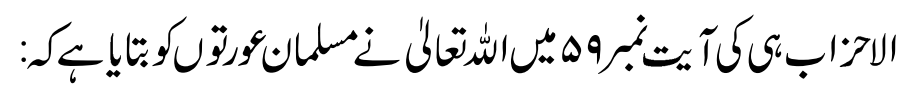

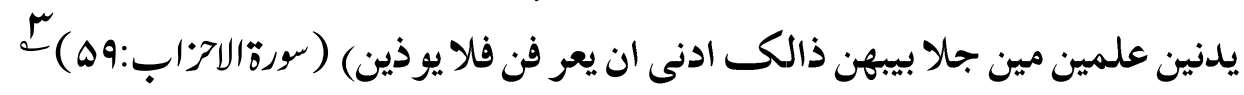
تزبم:

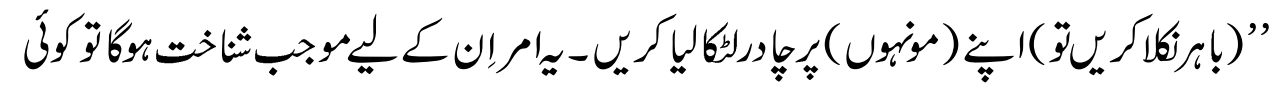




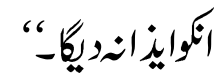

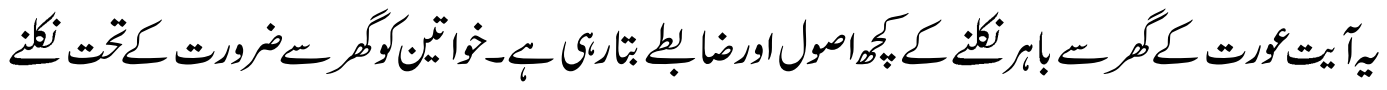

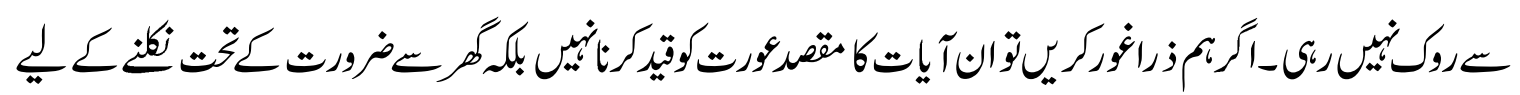

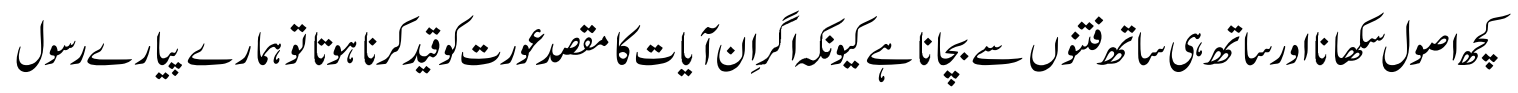

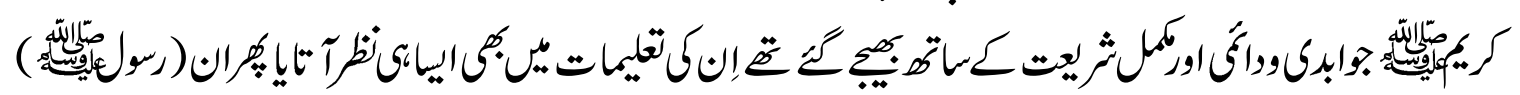

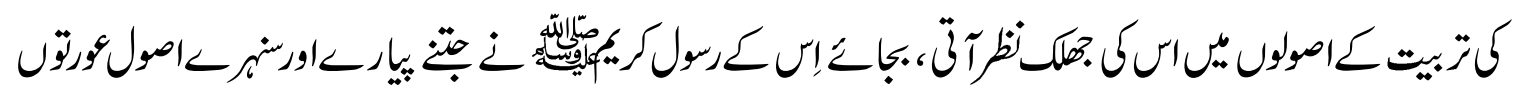

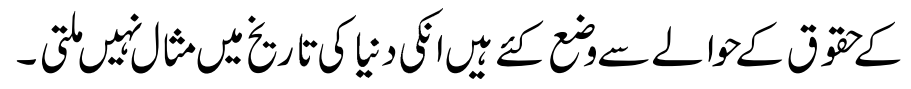

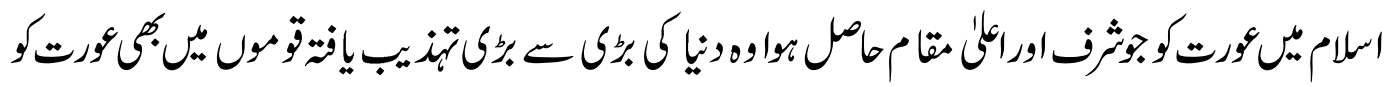

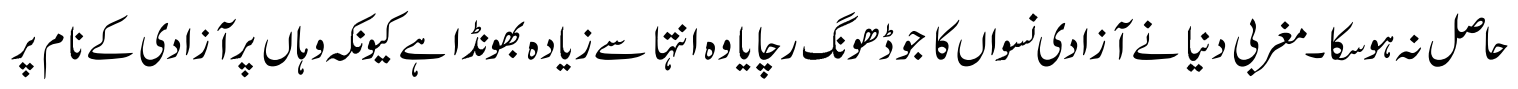

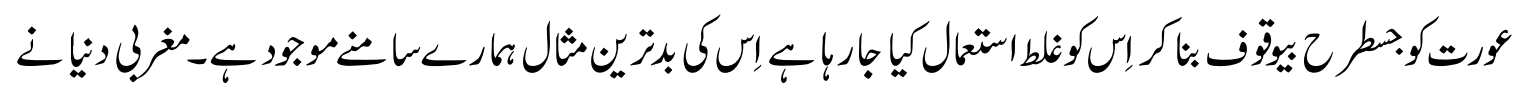

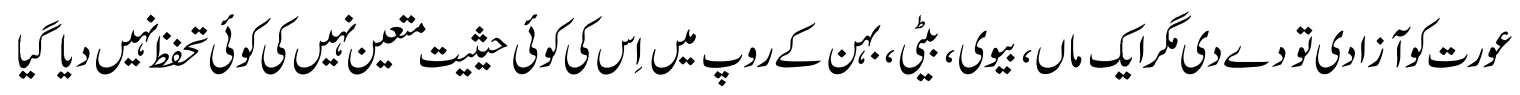

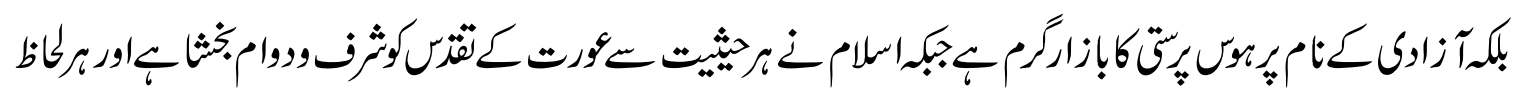

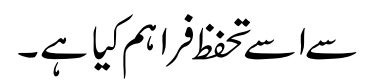

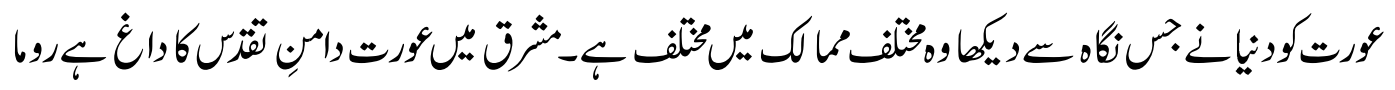

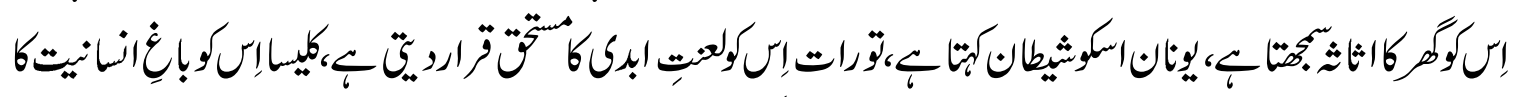

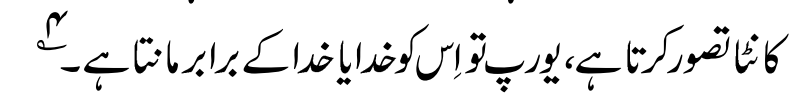

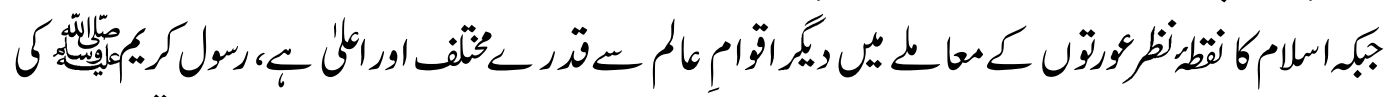

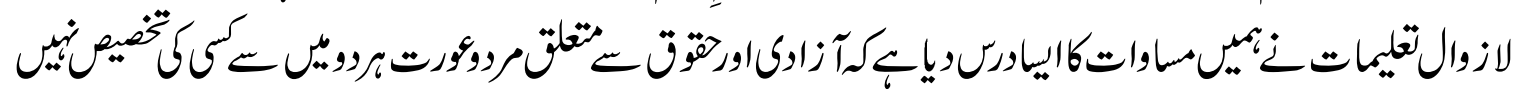

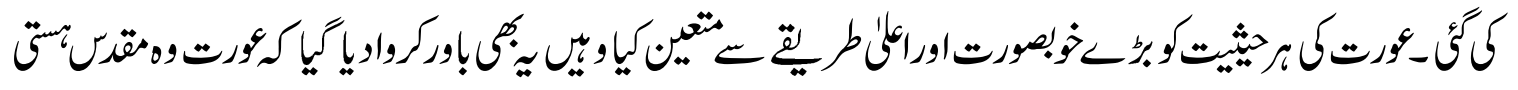

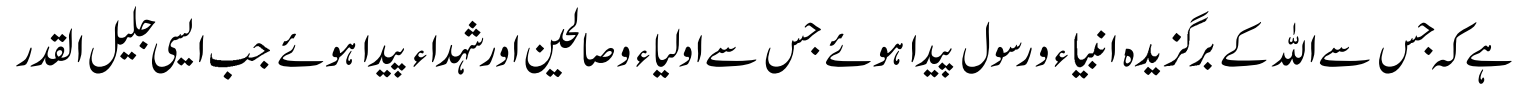

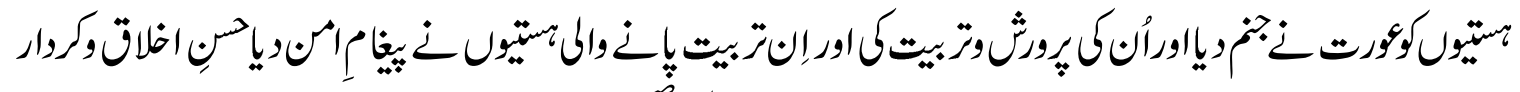

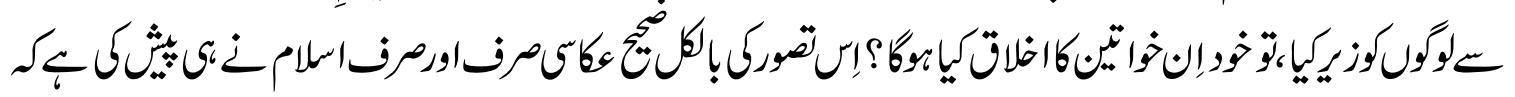




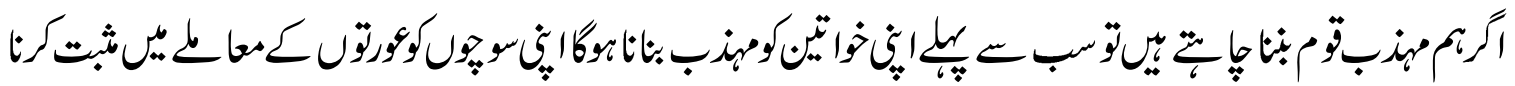

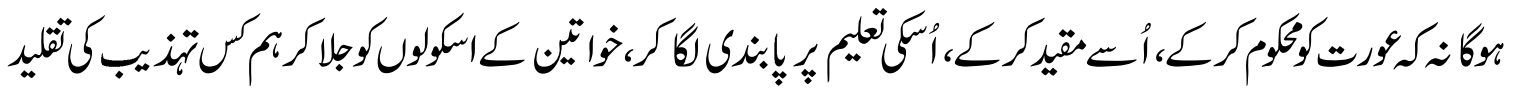

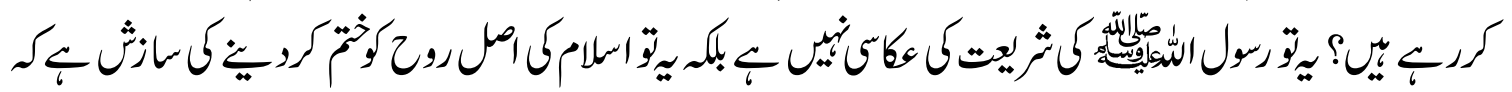

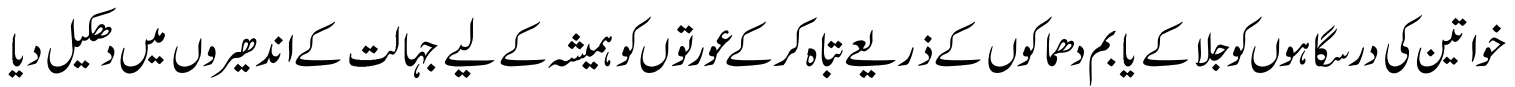

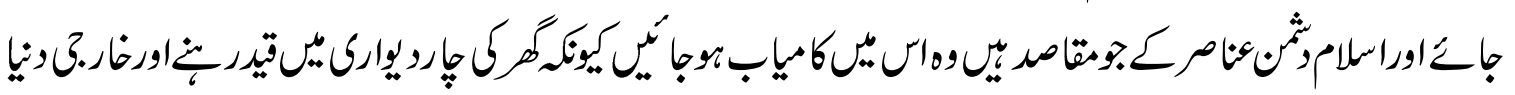

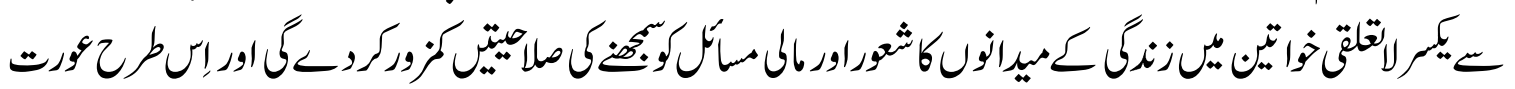

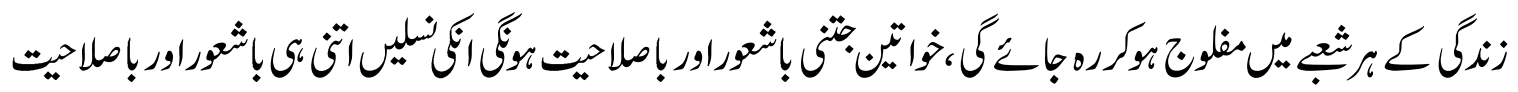

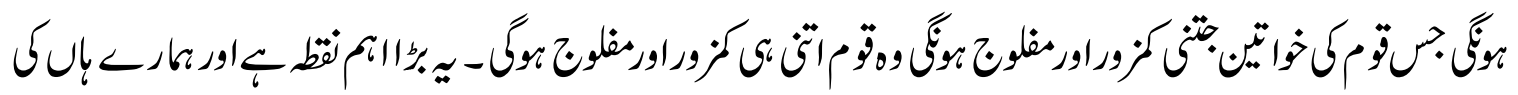

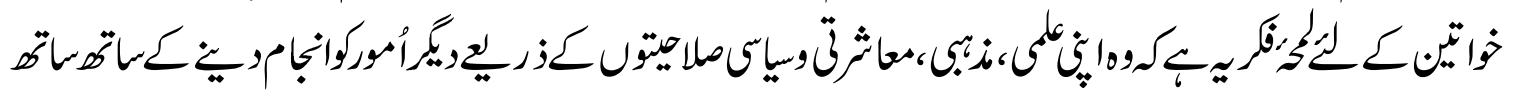

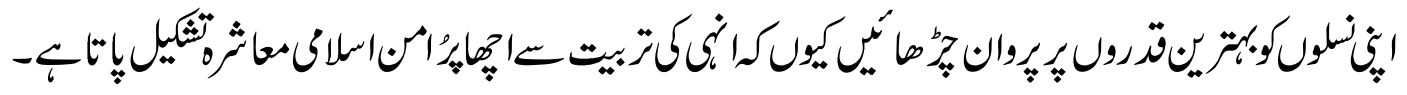

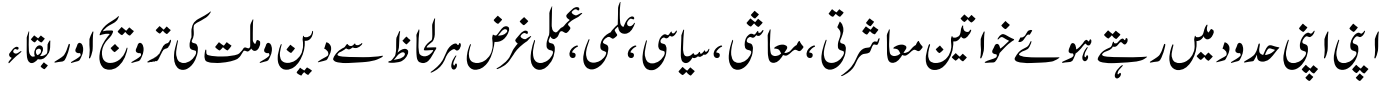

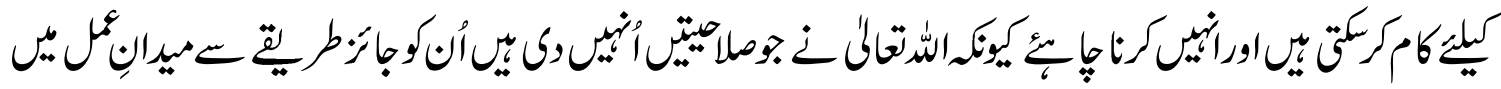

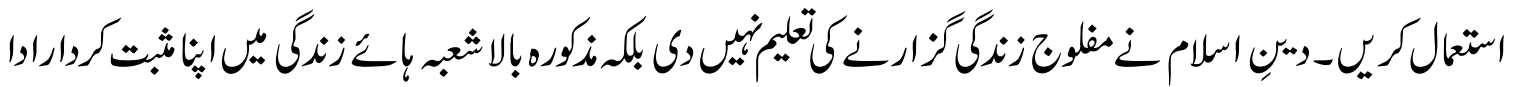

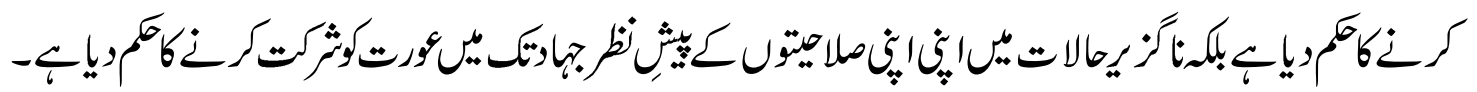

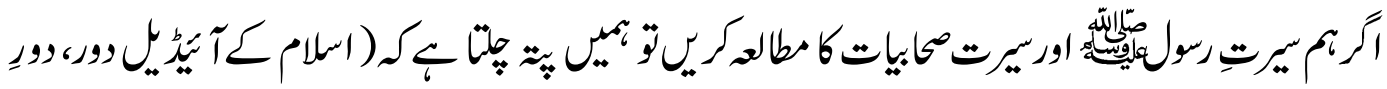

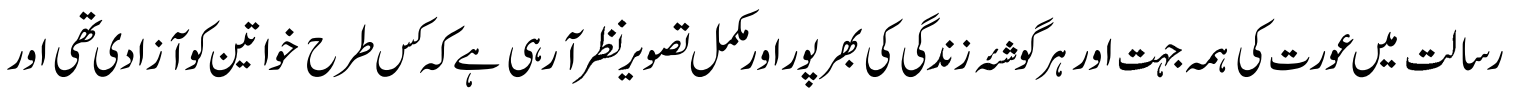

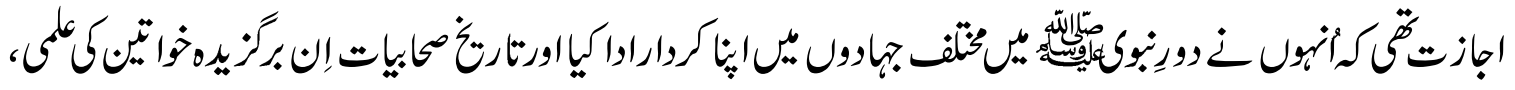

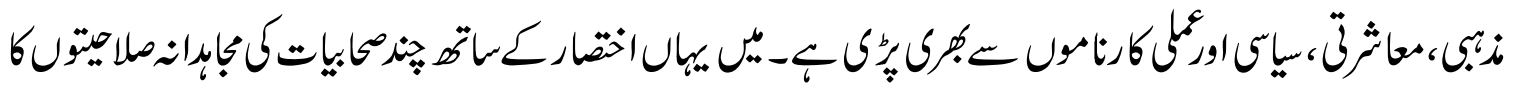

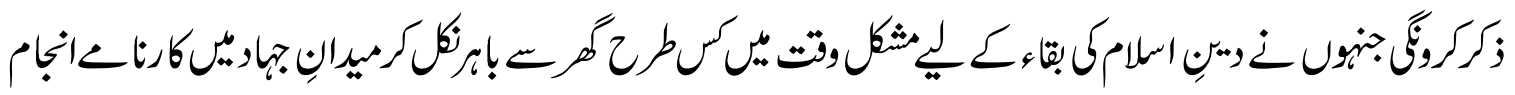

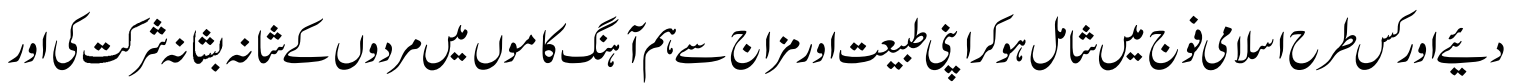

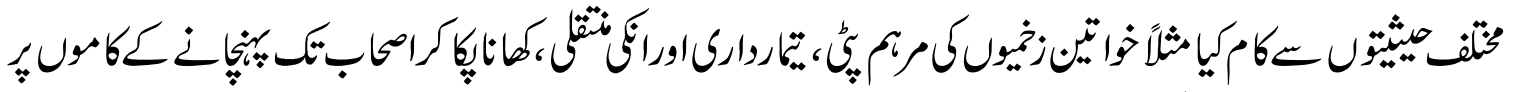

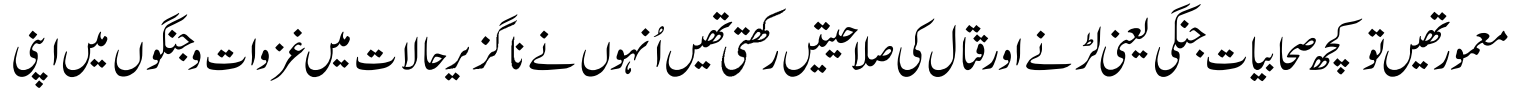




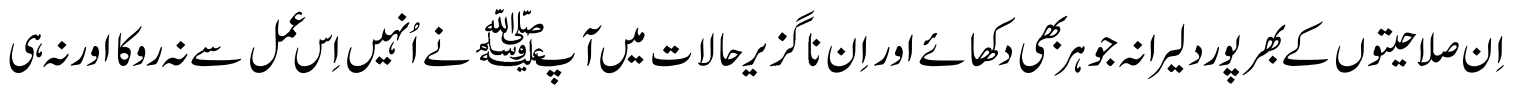

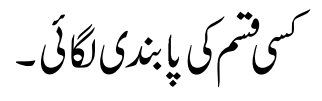

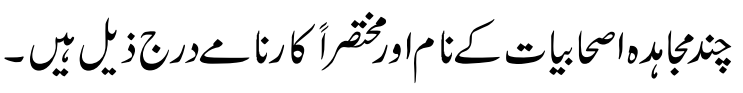

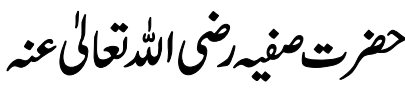

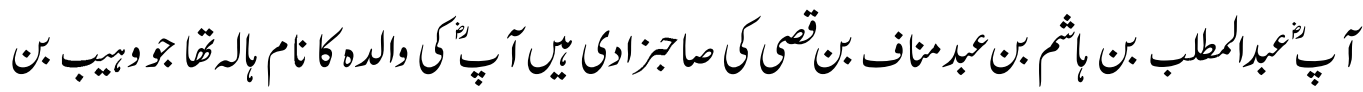

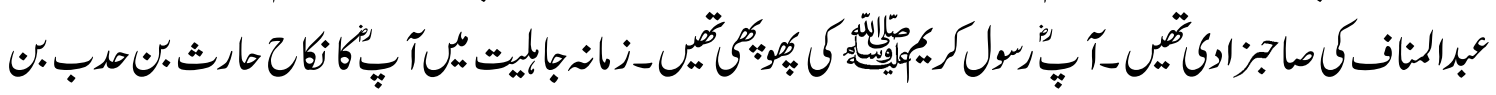

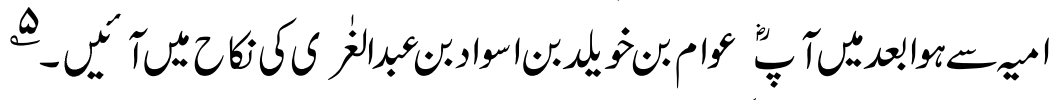

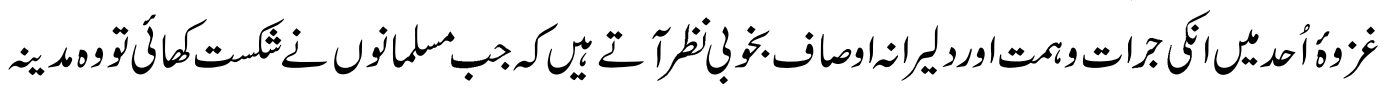

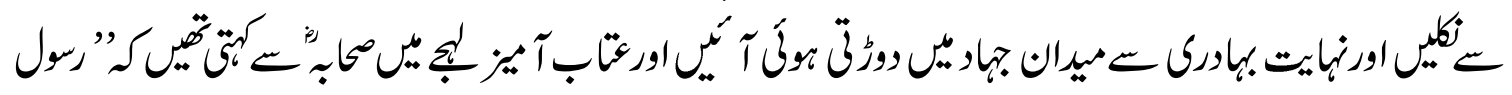

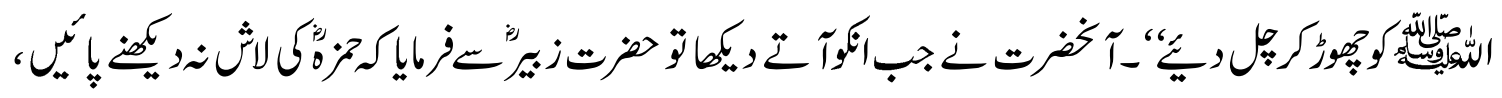

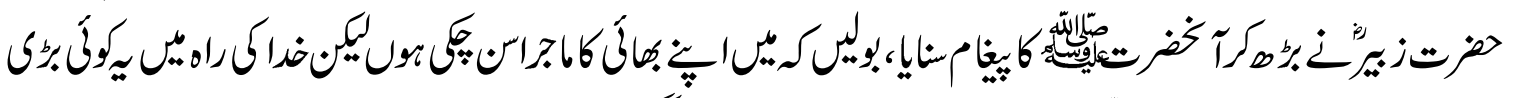

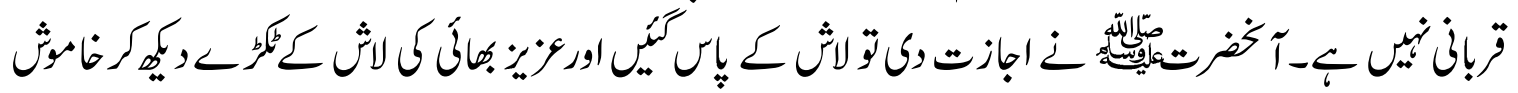

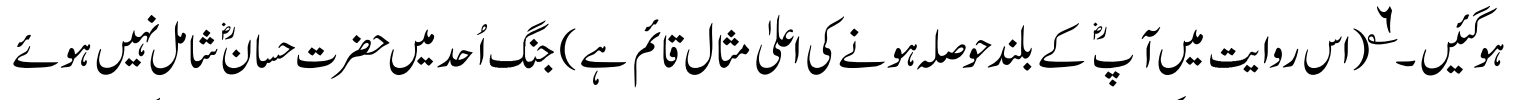

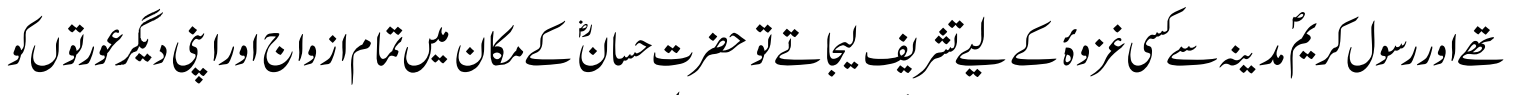

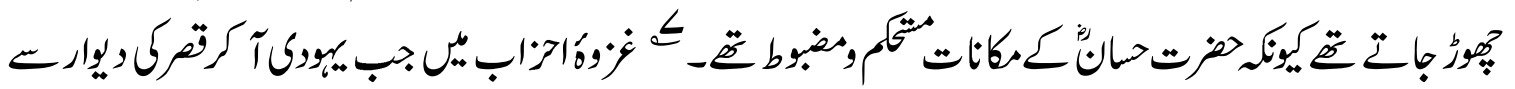

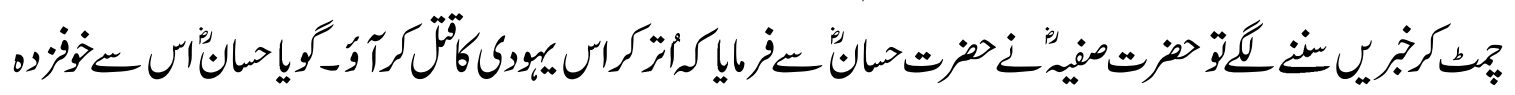

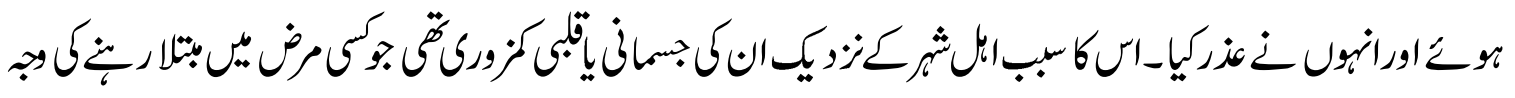

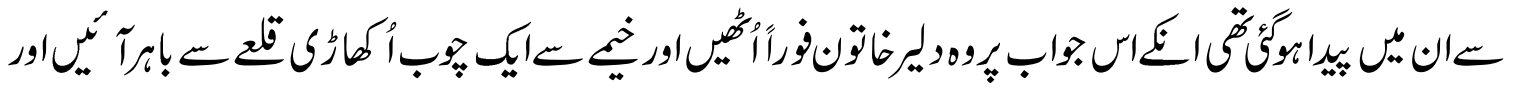

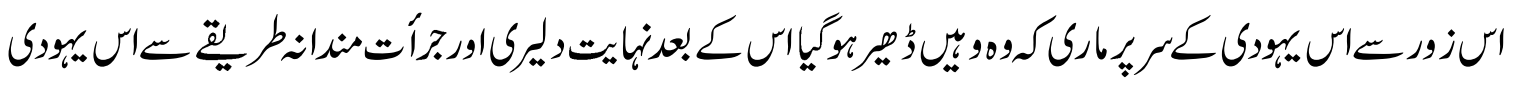

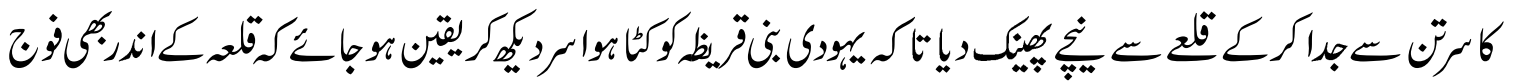

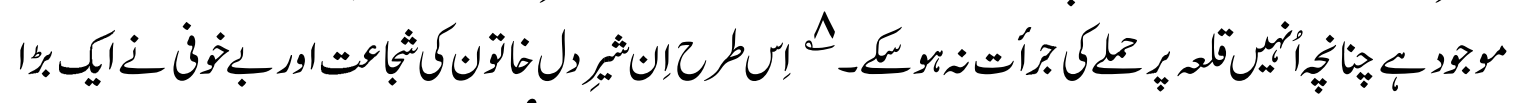

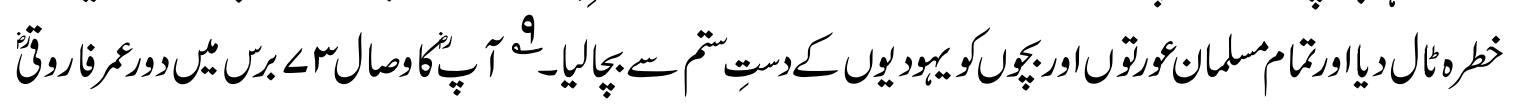




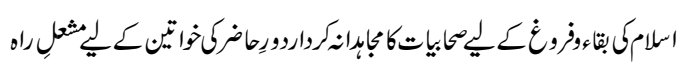

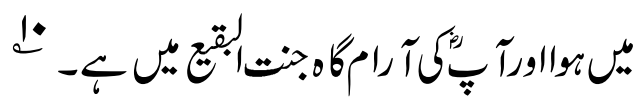

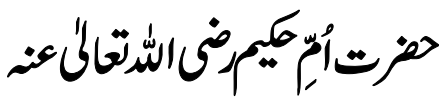

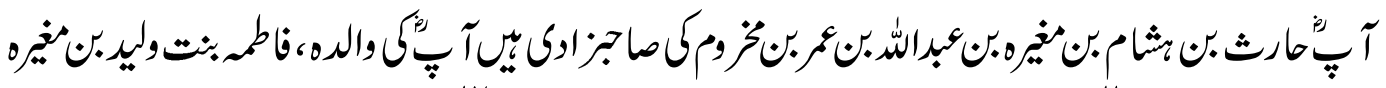

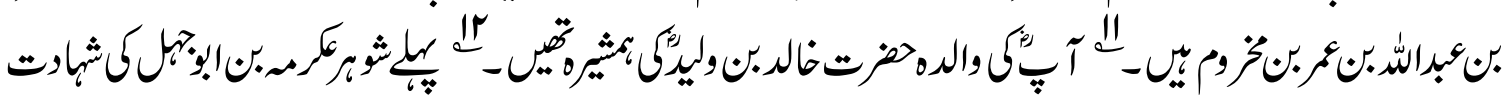

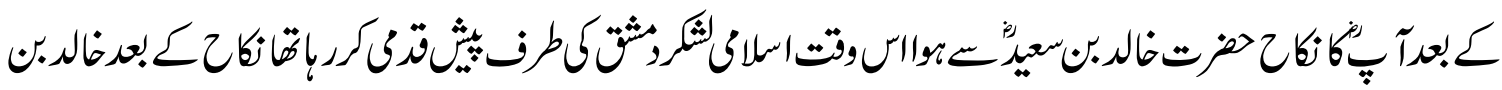

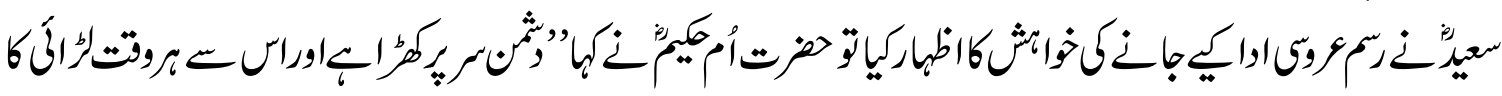

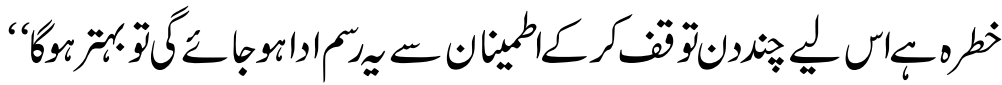

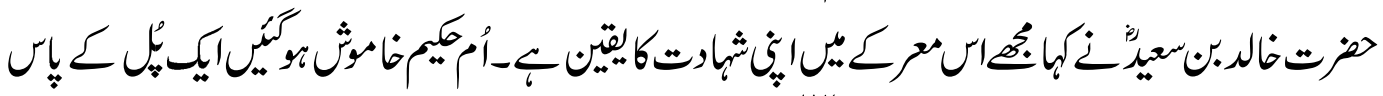

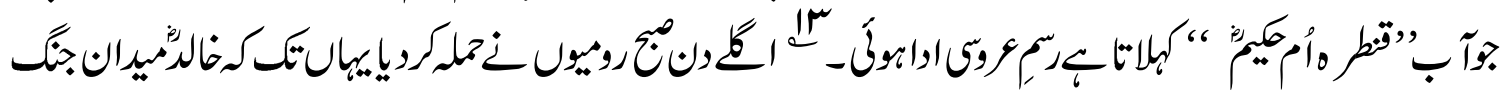

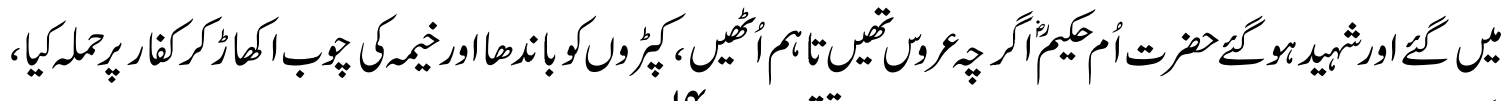

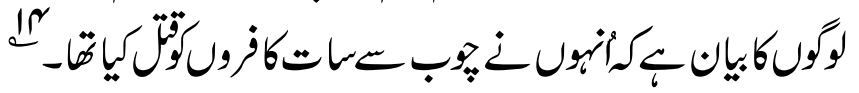

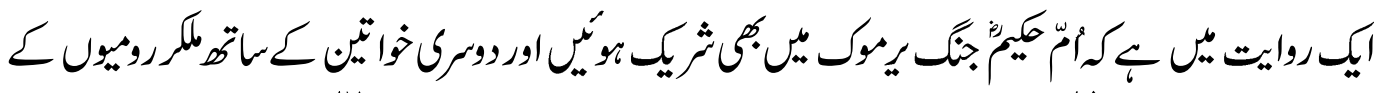

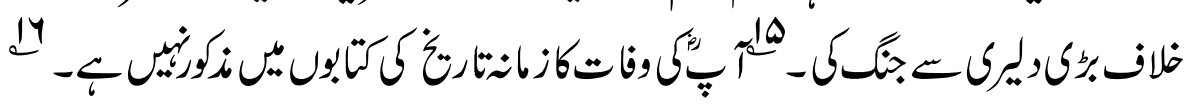

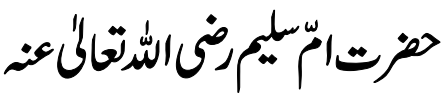

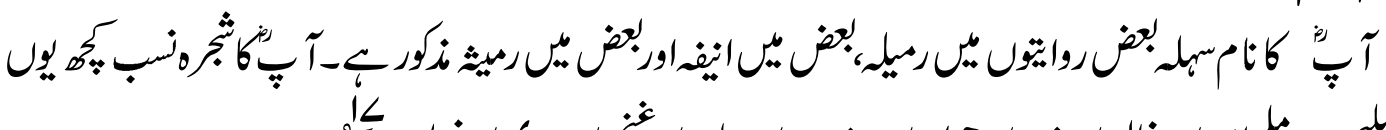

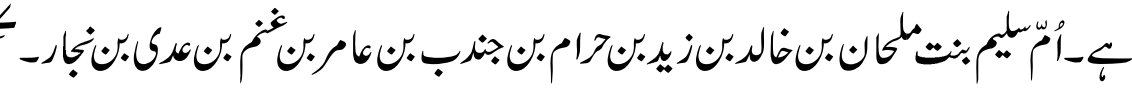

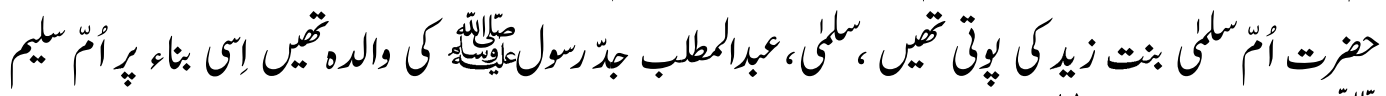

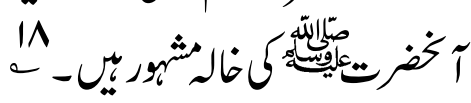

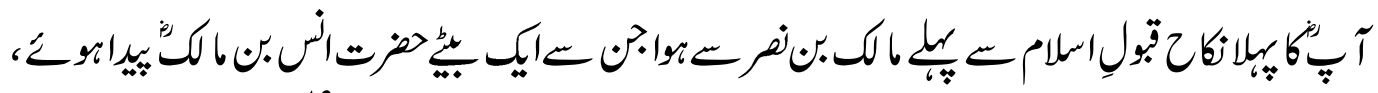

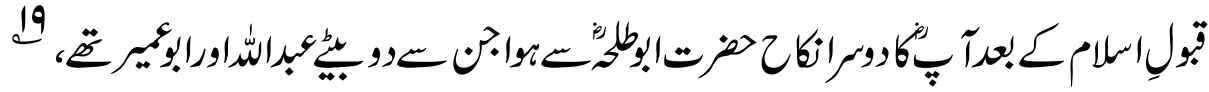

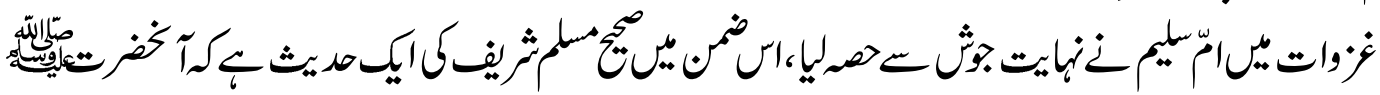


$<$

ثاكتئكيل

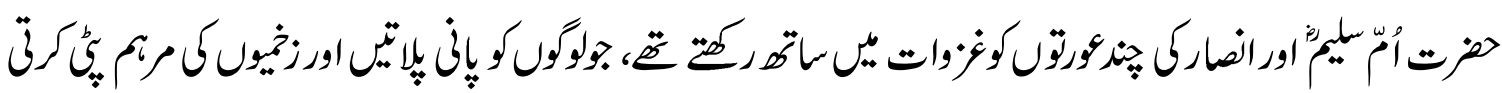

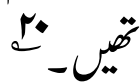

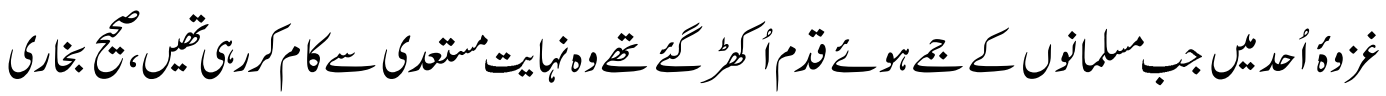

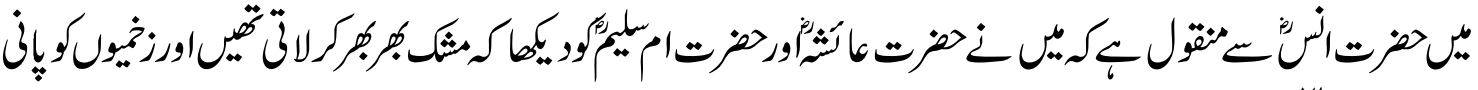

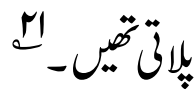

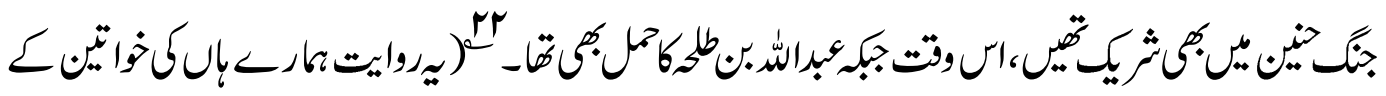

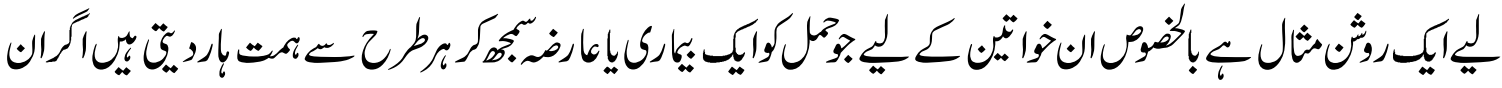

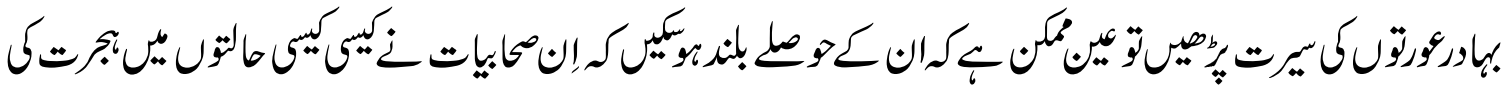

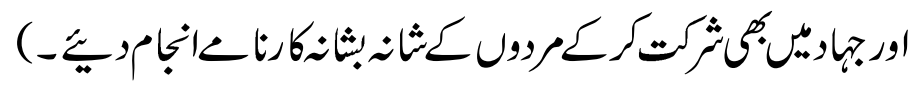

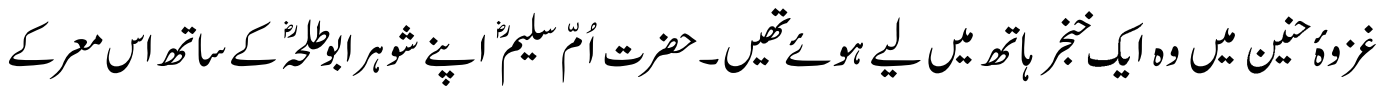

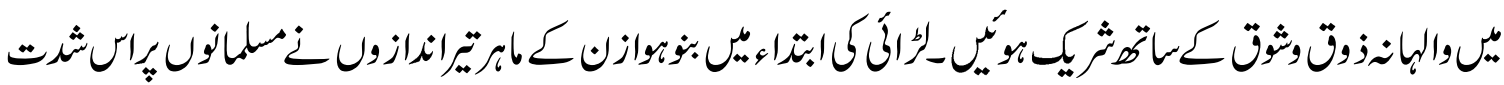

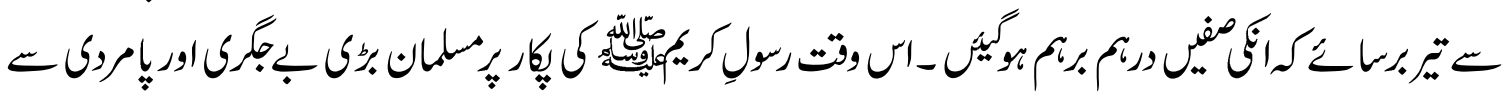

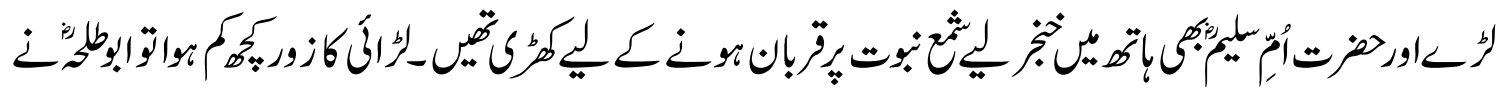

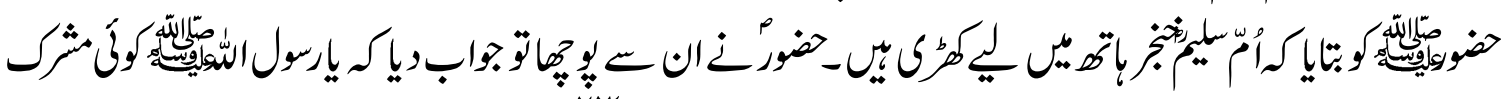

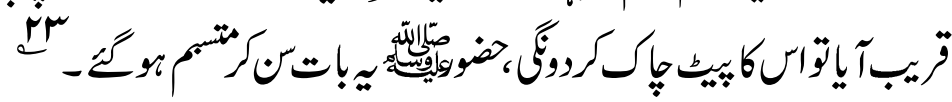

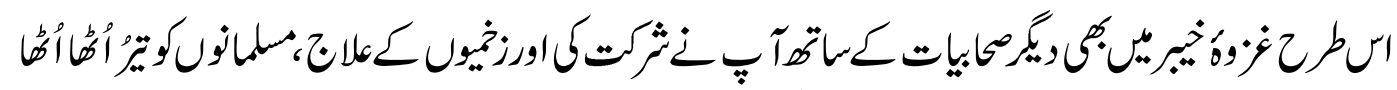

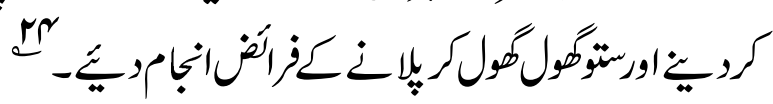

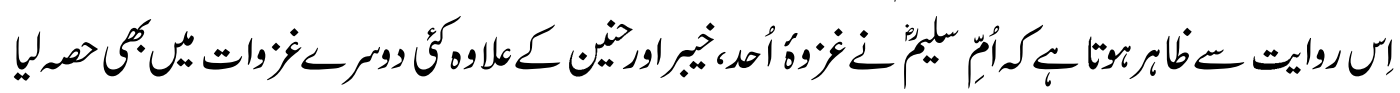

rat $-8 \%$

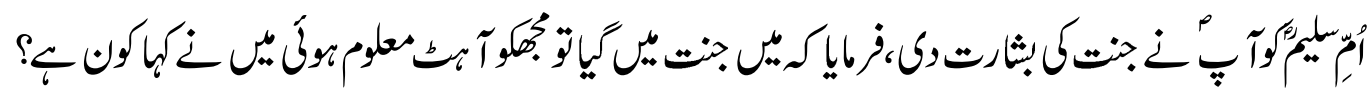

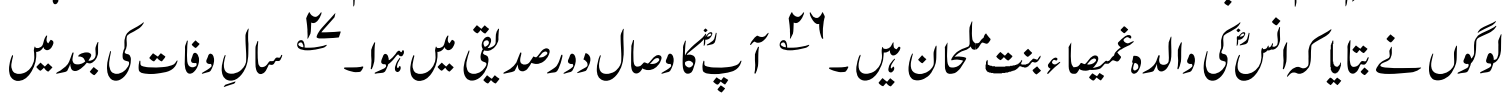

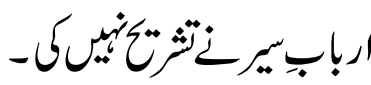




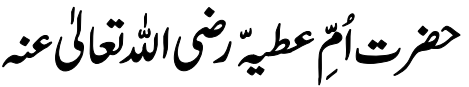

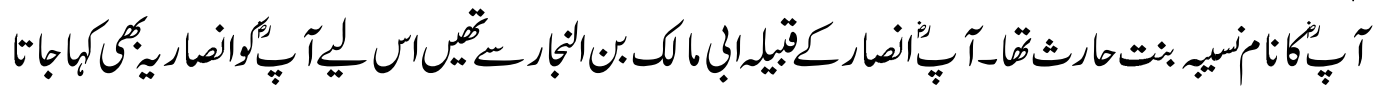

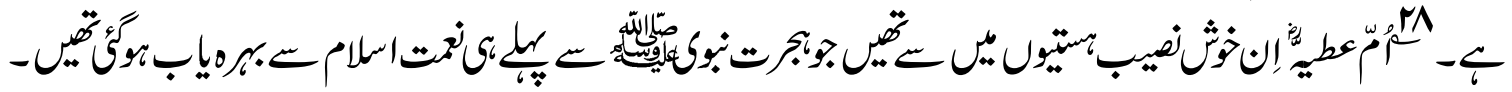

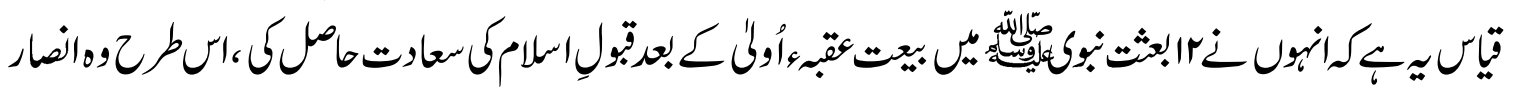

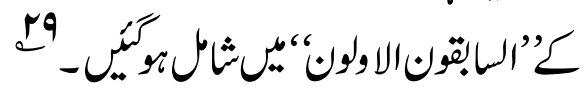

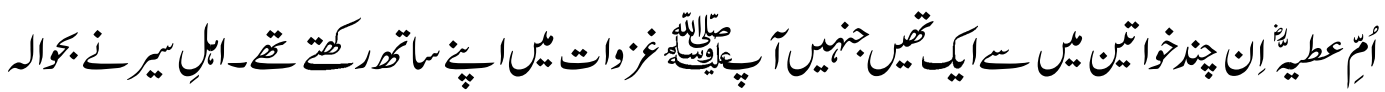

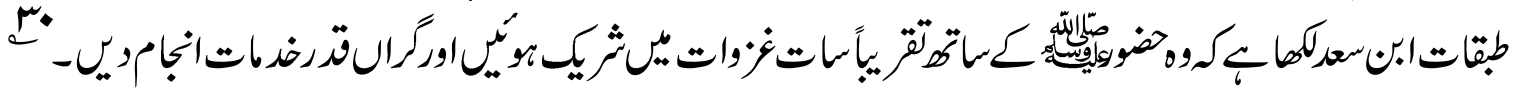

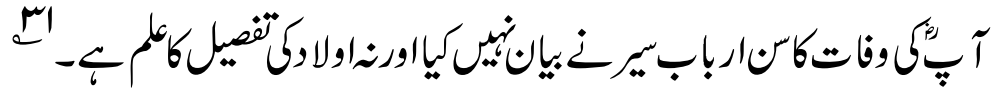

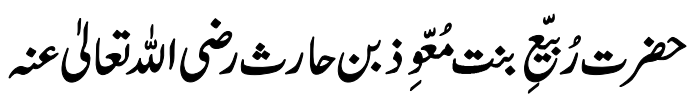

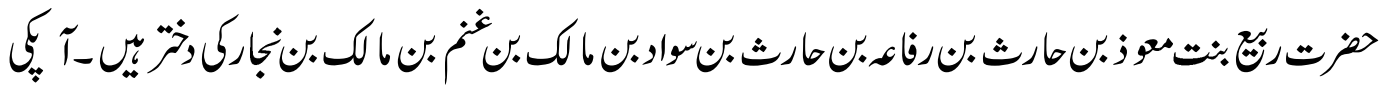

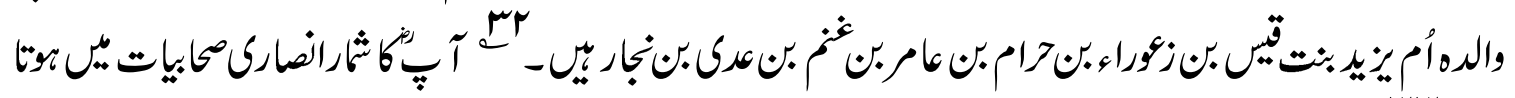

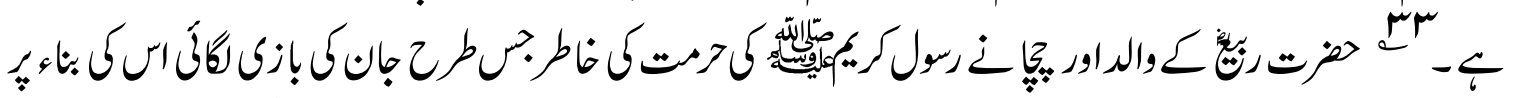

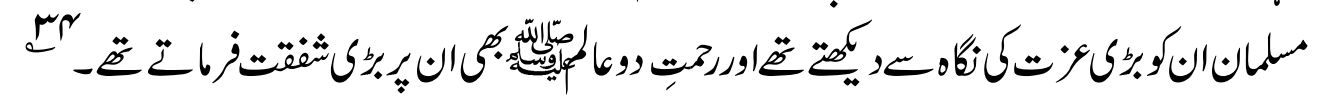

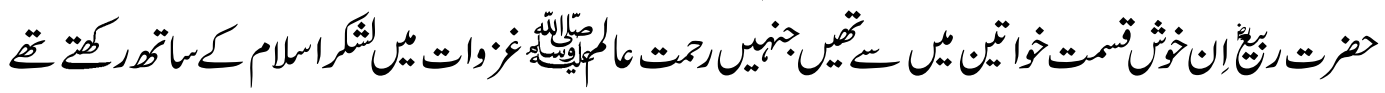

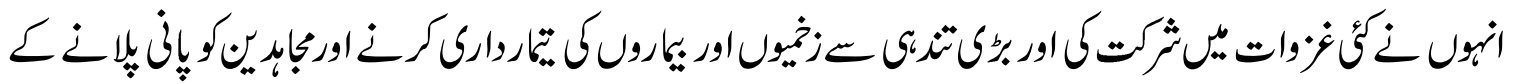

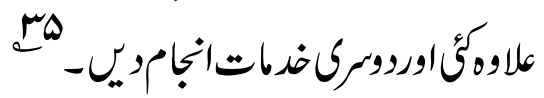

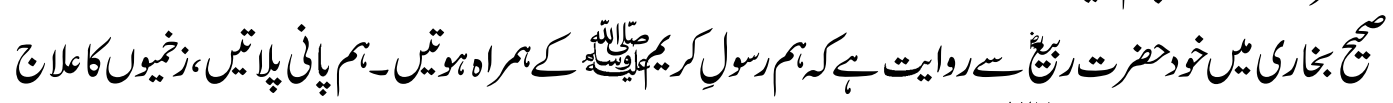

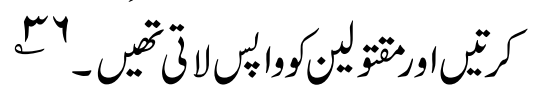

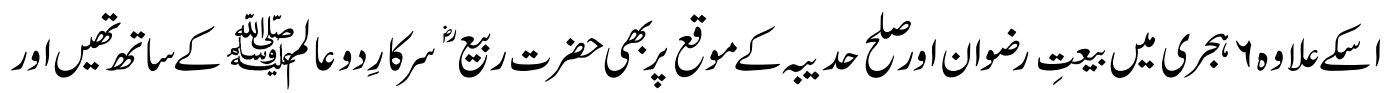

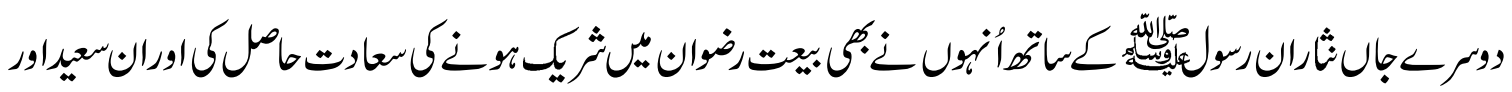

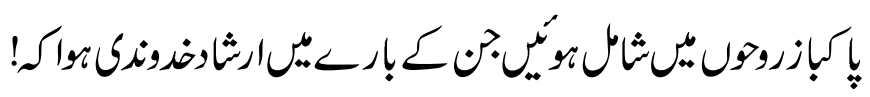

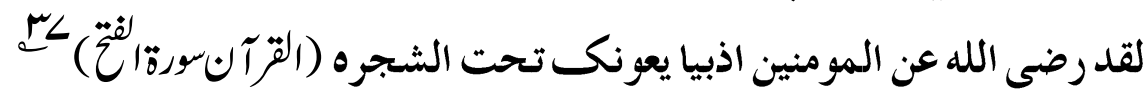




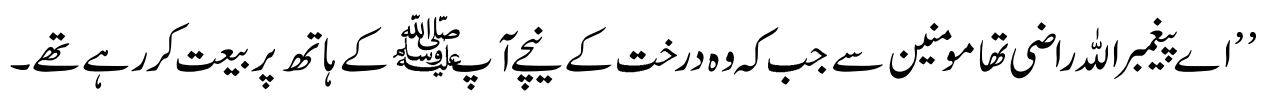

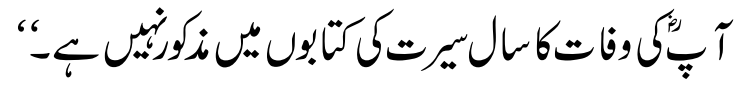

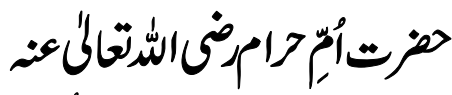

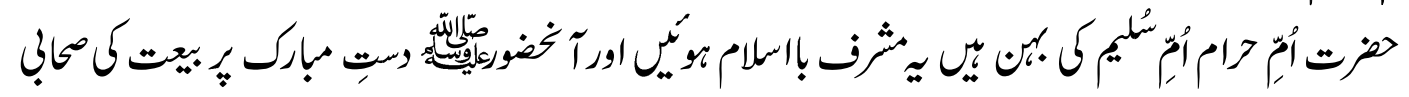

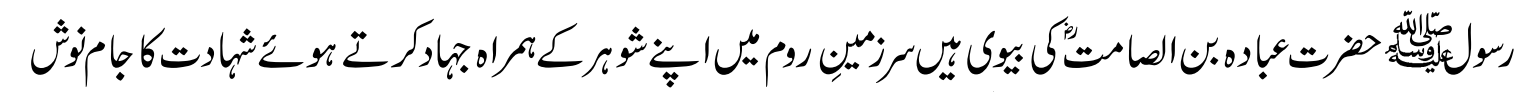

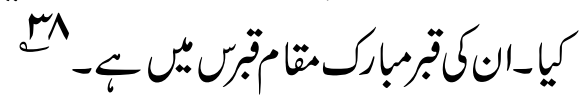

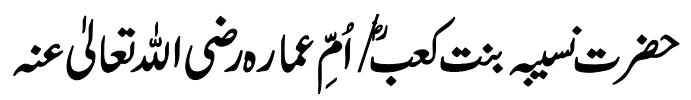

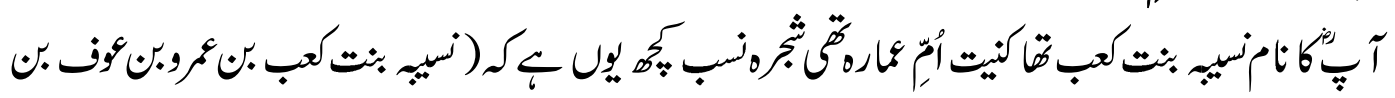

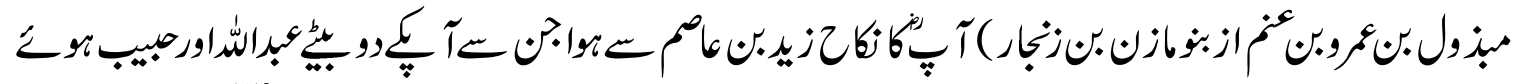

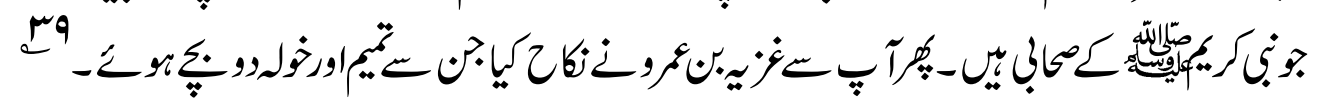

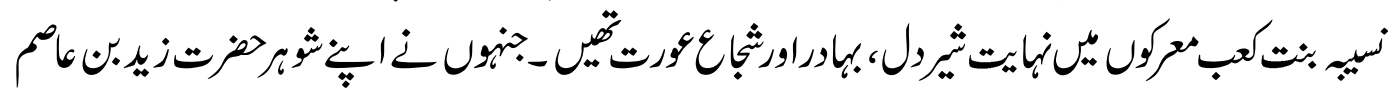

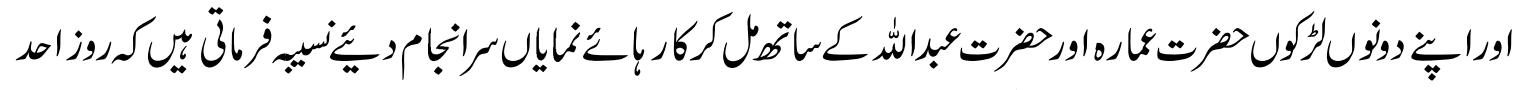

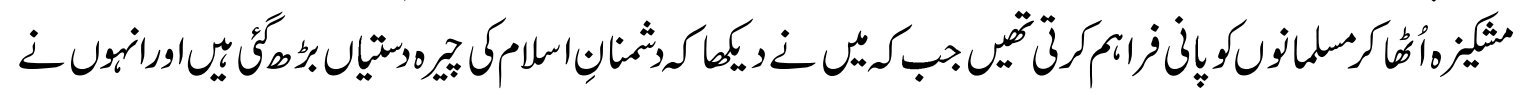

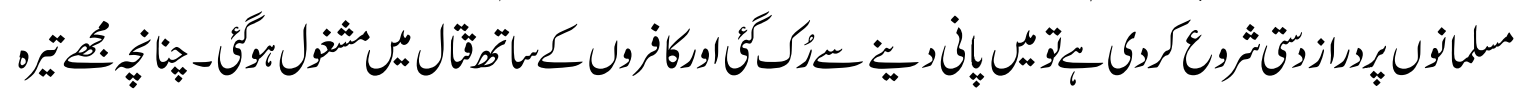

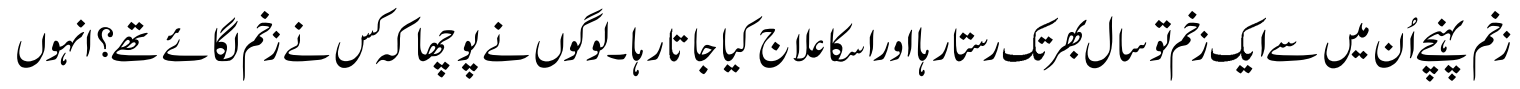

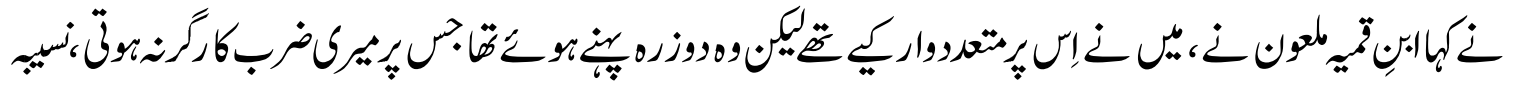

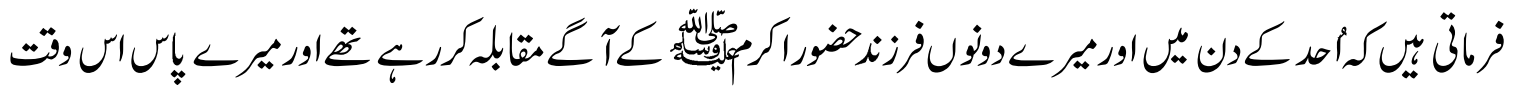

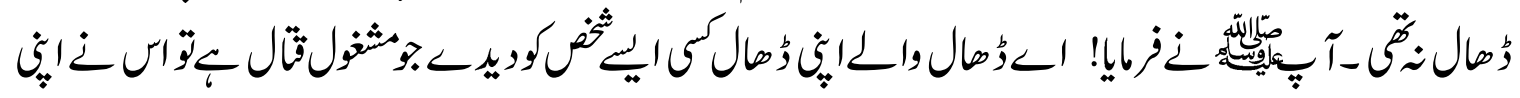

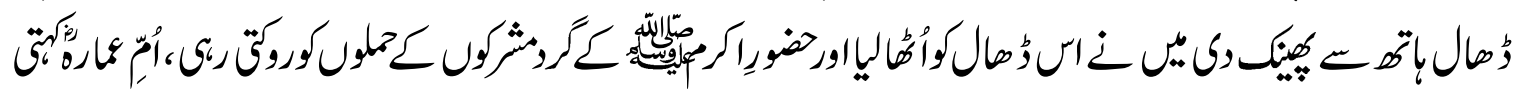

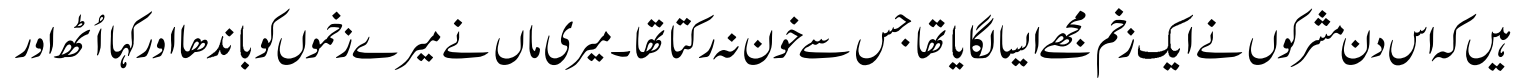

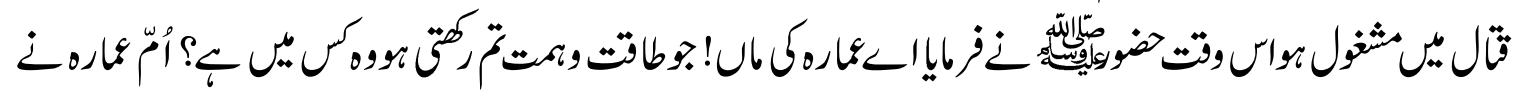




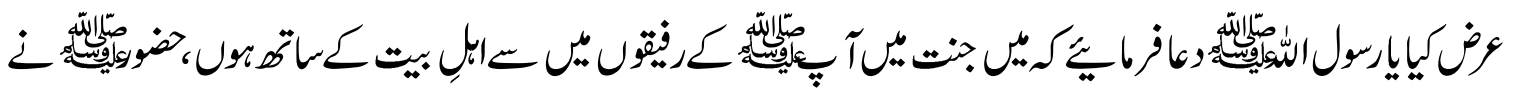

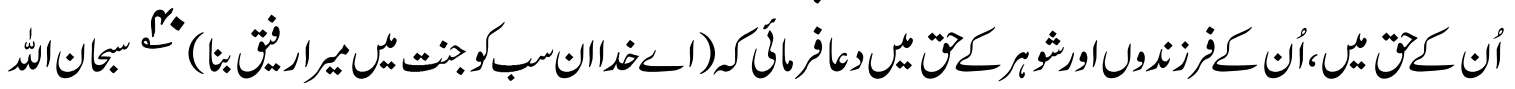

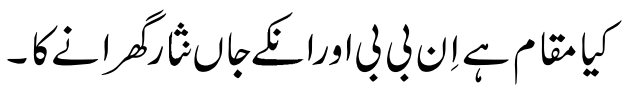

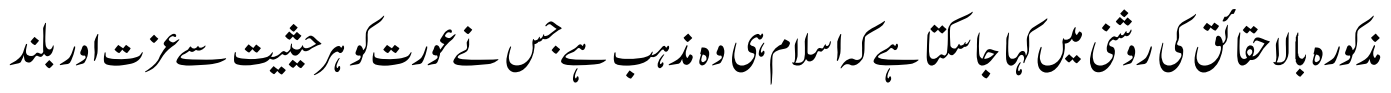

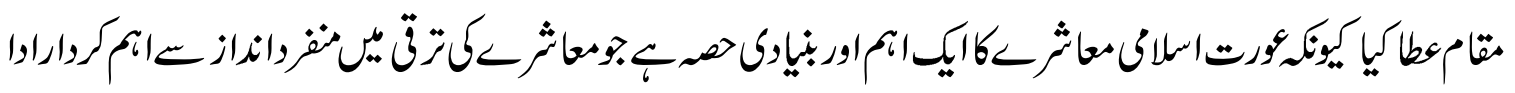

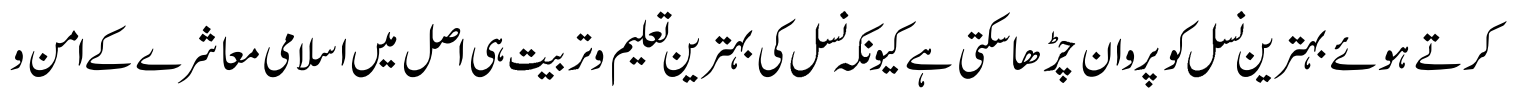

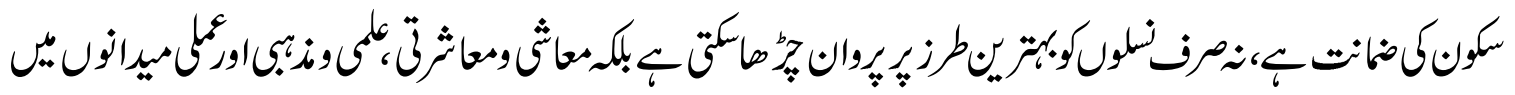

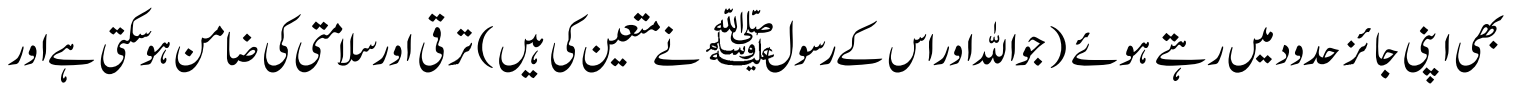

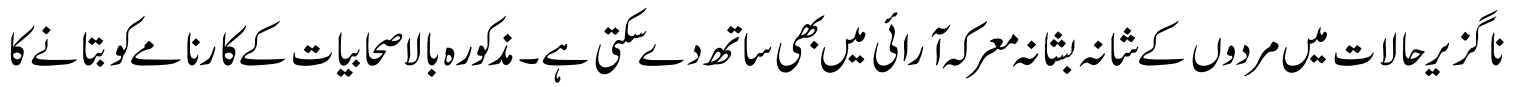

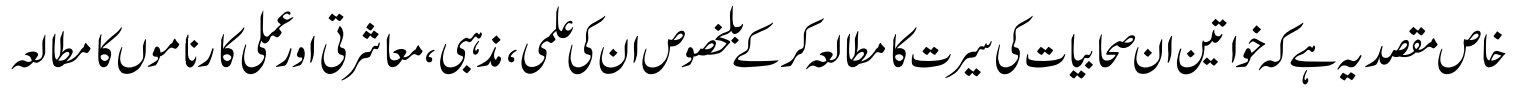

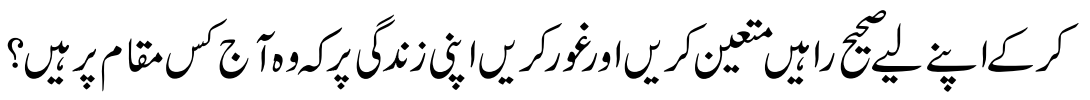

\section{קوالم جإت}

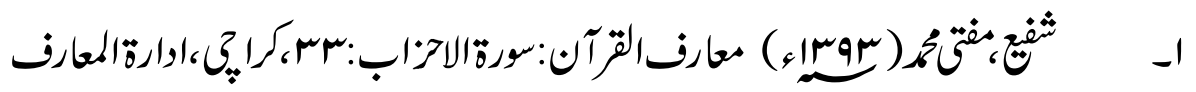

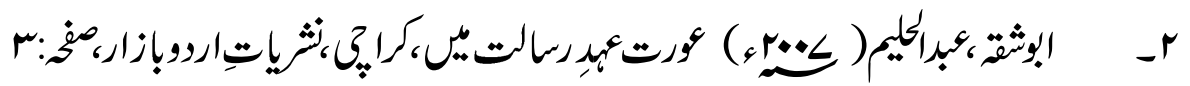

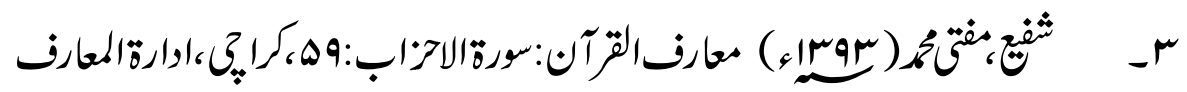

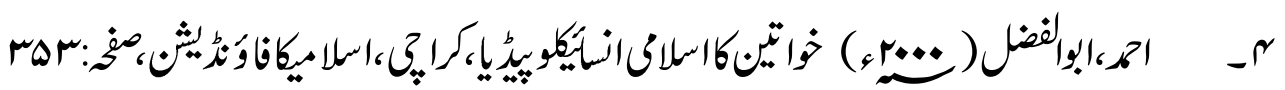

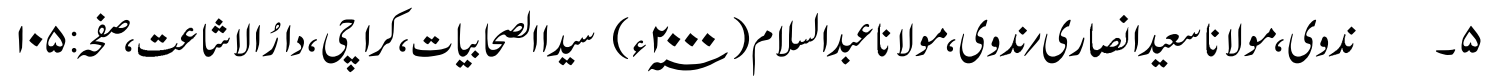

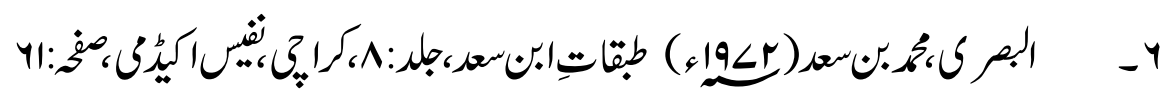

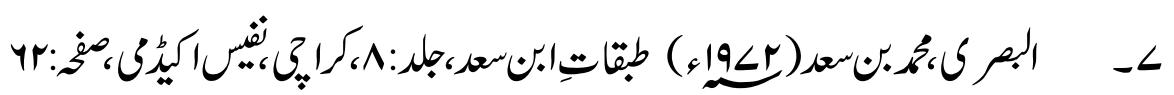

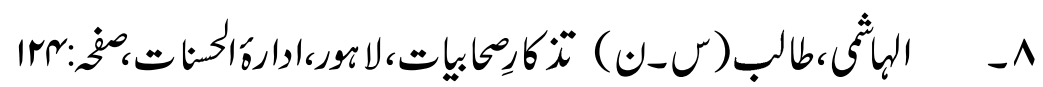




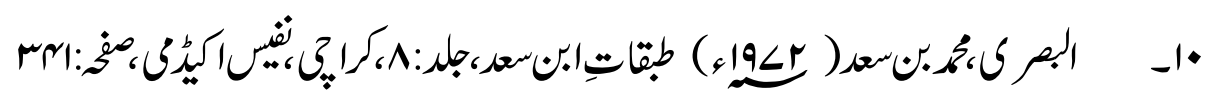

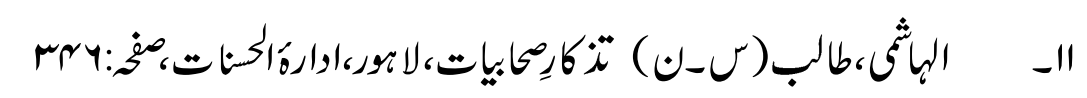

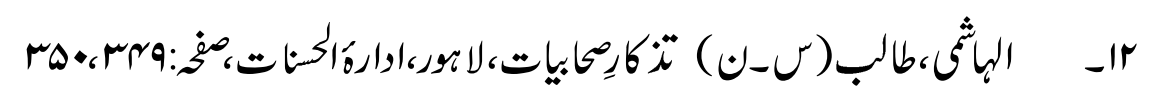

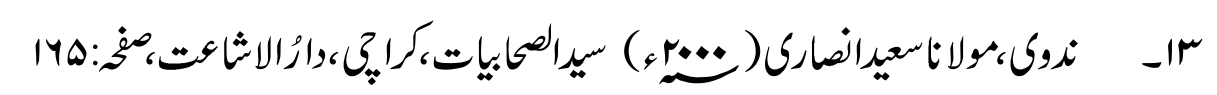

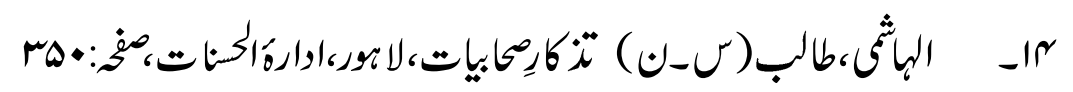
إيضاً

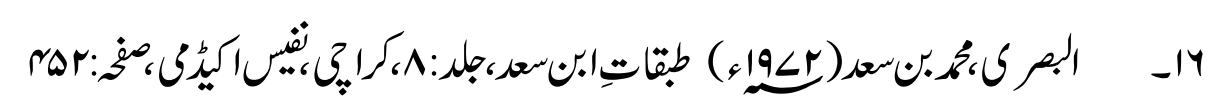

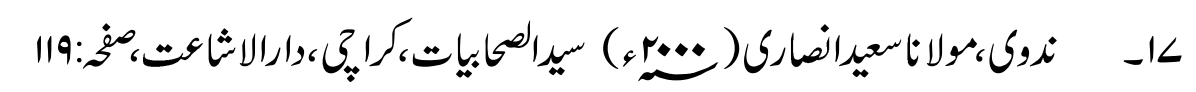

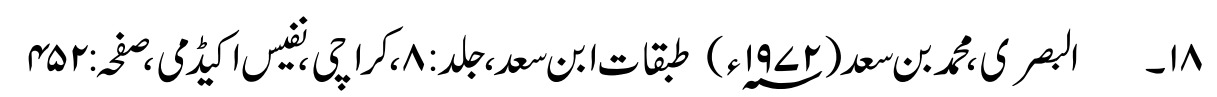

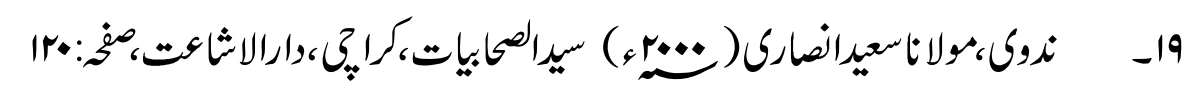

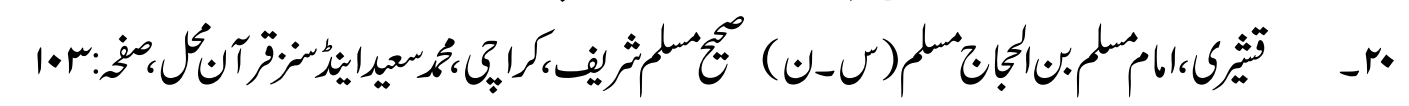

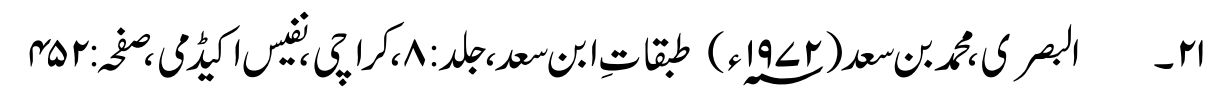
rr إيضاً إيضاً إيضاً

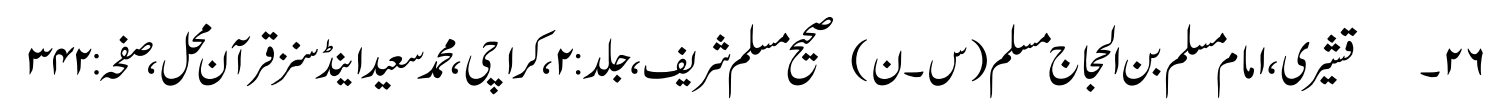

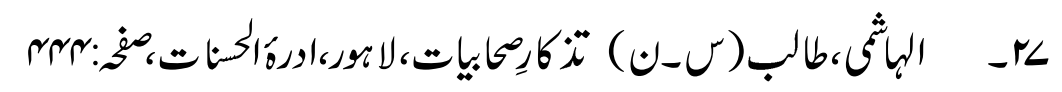

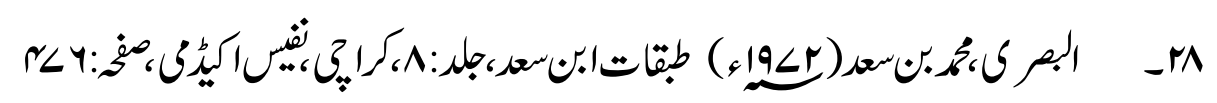

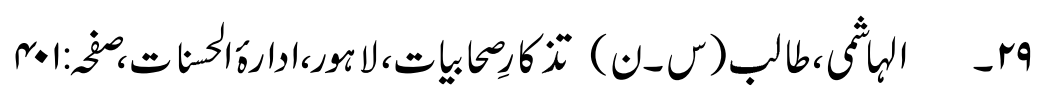

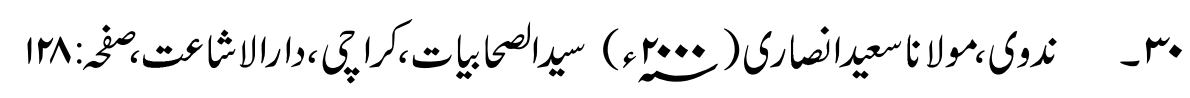




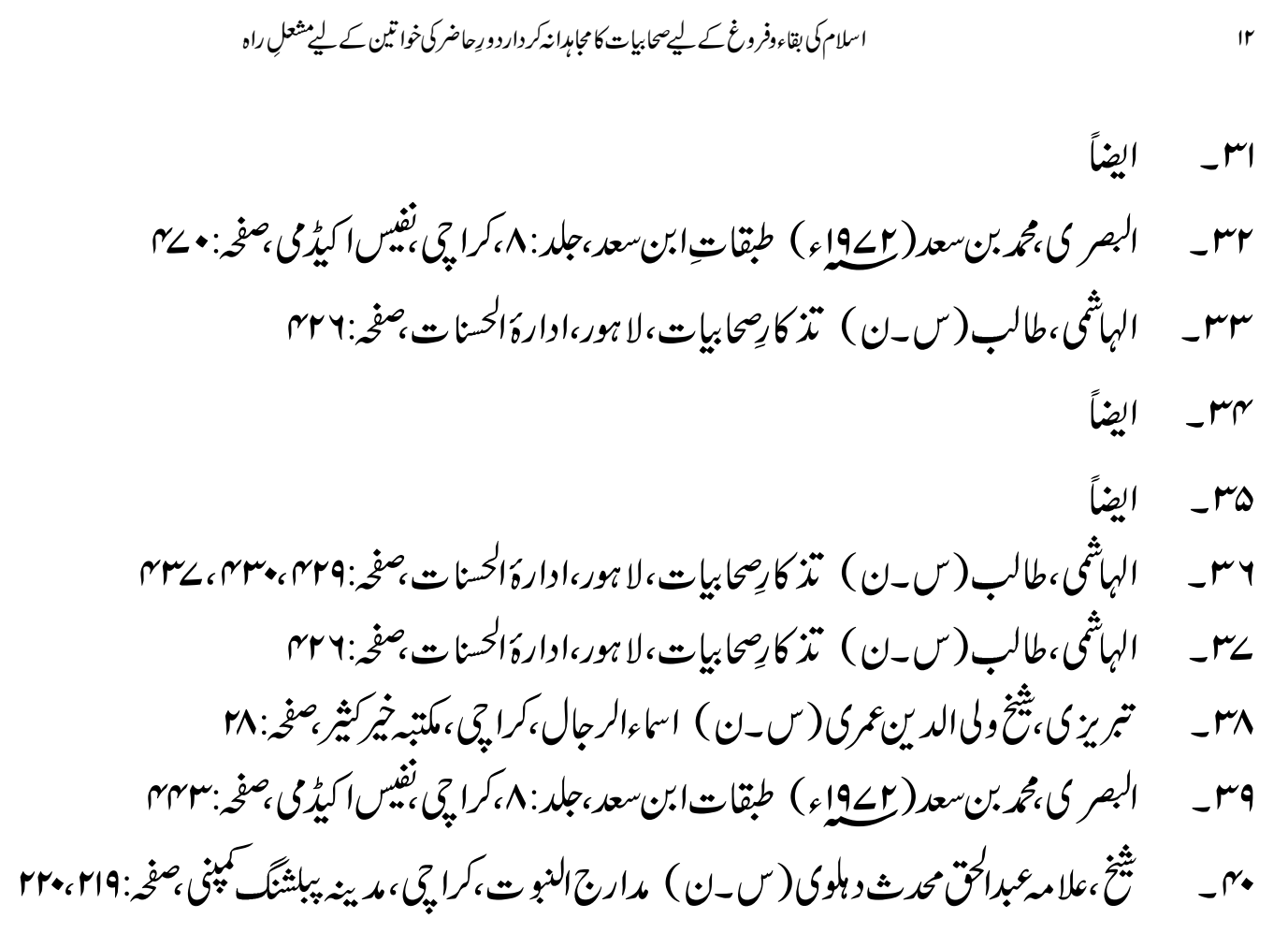

rr

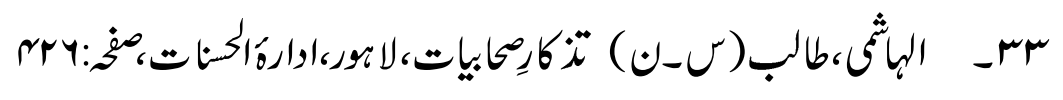

r

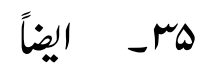



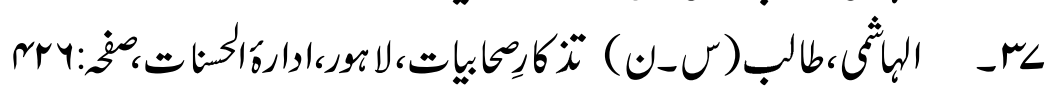

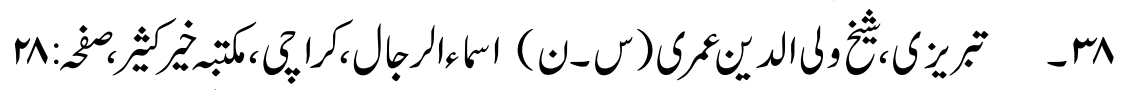

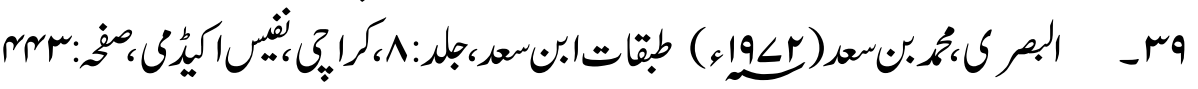

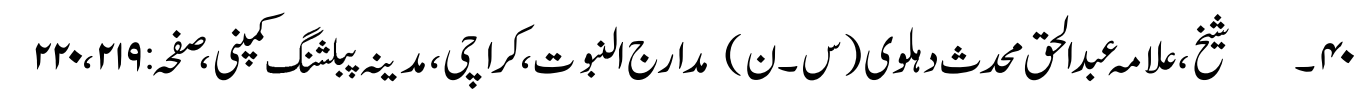

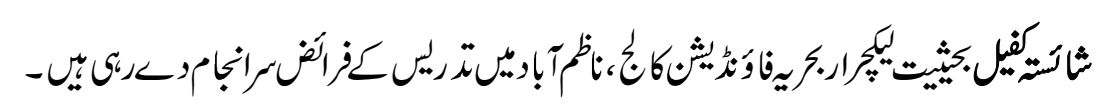

